\title{
THE CANADIAN REMOTE-SENSING PROGRAM
}

\author{
By J. MacDowall
}

(Canada Centre for Remote Sensing, Department of Energy, Mines and Resources, Ottawa, Ontario $\mathrm{K}_{1} \mathrm{~A}_{0} \mathrm{E}_{4}$, Canada)

Abstract. The principal elements in the Canadian national program in remote sensing are:

I. The ERTS receiving station in Prince Albert,

2. ERTS and airborne data processing facilitv in Ottawa,

3. ERTS and airborne photographic reproduction facility in Ottawa,

4. The airborne program,

5. The remote-sensing test sites,

6. The sensor development program,

7. Regional and speciality interpretation centres,

8. The necessary organization to manage the national program in remote sensing.

The Canada Centre for Remote Sensing (CCRS) has three operating Divisions: The Data Acquisition Division, the Data Processing Division, and Applications Division. New sensors are developed by the Centre with contracts to industry and universities. Photographic reproduction and distribution is handled by the National Air Photo Library (NAPL) of the Department of Energy, Mines and Resources.

Canada designed and constructed her own ERTS ground receiving station at Prince Albert, Saskatchewan. It was put there because of the existing $26 \mathrm{~m}$ diameter antenna, near the middle of the country. Data from the extreme east of Canada are not received at Prince Albert. There are plans for an east-coast station.

A quick-look display system has been incorporated into the Prince Albert station. It comprises a high-quality television display and a $70 \mathrm{~mm}$ camera. Prints from these negatives and microfiche copies of them (ERTSFICHE) are produced under a franchise arrangement and mailed out within two days of the satellite pass. About 7o ERTS images of Canada a day are received at Prince Albert. A tape record of the raw ERTS data is made and sent for processing to Ottawa.

This tape is handled by the Ottawa ERTS data processing facility. $70 \mathrm{~mm}$ monochrome images of each of the four ERTS-I multi-spectral scanner wave bands and computercompatible tapes are produced by the facility. PDP-io computers are also utilized for image inventory, the image analysis research of the Applications Division of CCRS, and processing airborne data.

An inventory of ERTS images is compiled in the CCRS computer as they are created together with comments on cloud cover and quality. Orders for the images are received by NAPL, checked against the computer inventory, and filled as soon as possible. The average time to filling such orders was about four weeks in December 1973, though fluctuations in service and back-log problems occur owing to occasional equipment malfunctions. An experimental regional capability of quizzing the image file is being considered. This consists of a remote terminal to the CCRS PDP-Io computer which can operate from any telephone.

The photographic products, in both colour and monochrome, maintain the full resolution of the ERTS system. NAPL also handle the reproduction and distribution of all airborne remote-sensing data from the full range of multi-spectral information present in the tapes. 
CCRA has four aircraft equipped with a wide range of photographic sensors, far-infrared scanners and radiometers, and some newly developed special-purpose sensors such as a chlorophyll spectrometer, a laser fluorosensor, and a microwave scatterometer and radiometer. These are available across Canada on a partial cost-recovery basis. Over the past three years, a series of research and development contracts to construct new equipment for clearly defined needs such as sea-ice thickness measurement, have been let by CCRS to Canadian industry and universities.

The Provinces of Ontario, British Columbia, Manitoba, and Alberta, have established their own remote-sensing centres, and Speciality centres exist at the Canada Centre for Inland Waters at Burlington for limnology, at the Department of the Environment, Ottawa for hydrology, at the Forest Management Institute, Ottawa for forestry, and at the Department of the Environment in Victoria, B.C. for oceanography.

The information content of satellite data is so high that it is not possible to display all the information in one colour print. Computer programs have been developed and special hardware systems are being acquired so as to make a statistical analysis of spectral signatures on the ERTS tapes.

\section{DISCUSSION}

C. W. M. Swithinbank: You said that your "quick-look" ERTS images are distributed very quickly but that they pay a price for this in terms of reduced resolution. Are your "slow-look" images as good as those available from NASA or USGS?

J. MacDowall: As far as we can tell the quality of both Canadian and U.S. products is similar with respect to resolution and mapping accuracy. We do not use our images for radiometric measurements, preferring the tapes for such work, so we do not necessarily preserve radiometric accuracy with the images. We will be applying radiometric corrections, however, to reduce banding.

R. S. Williams, JR.: As long as the United States operates an international data centre (EROS Data Center) at Sioux Falls, South Dakota 57 198, U.S.A., for the dissemination of real-time and tape-record data from ERTS, the data are available to all at a nominal cost. With the possible future proliferation of ground receiving stations on a global basis, two problems of data access cause concern: cost and availability. A particular country may choose to restrict access to ERTS data which it has received directly, and/or it may charge an absurdly high price for those data it chooses to make available.

The United States, in supporting such receiving stations, should insist on data access (including distribution of data catalogues) and reasonable cost for data. Even better would be exchange of at least $70 \mathrm{~mm}$ imagery and/or tape-recorded data between stations. Another solution considered in the United States is that an international data center should serve as depository for ERTS data from all countries which operate ERTS receiving stations, so that scientific data of global significance may be available to all.

MAGDowall: We cannot receive data from the extreme east of Canada and so have to get this from the U.S.A. Our experience is that it takes far too long to get the data from the U.S.A., who do not have a "quick-look" facility to give us data within hours of the satellite's pass; this is why we are building a second station. The cost of Canadian data is not high, being similar to the U.S. costs, but, as you say, other countries may wish to charge on a different basis. Regarding the data rights of sensed countries, we believe this to be an urgent matter for international discussion and agreement. 